
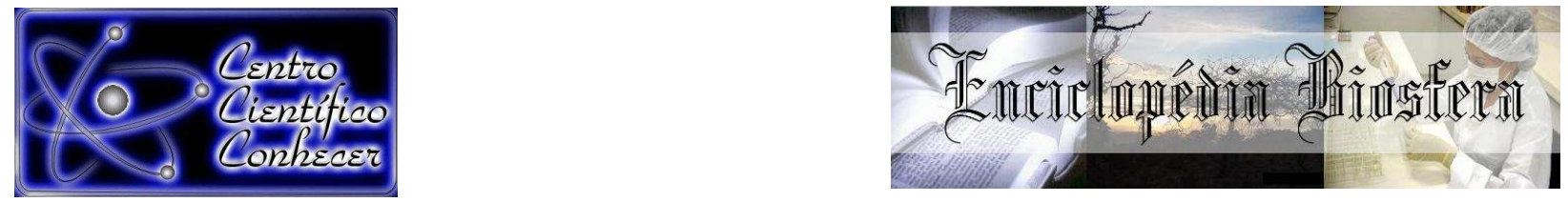

\title{
TERRITÓRIO E GEOGRAFIA ESCOLAR: REFLEXÕES DIDÁTICAS A PARTIR DA ATUAÇÃO DE ALUNOS BOLSISTAS DO PIBID
}

Leovan Alves dos Santos ${ }^{1}$ Rodrigo Rodrigues Freire Gomes ${ }^{2}$ Rafael Alonso Jeronimo Corvalan ${ }^{2}$ Rafael Denis Teixeira de Cunha $^{2}$

1 Mestre em Geografia pela Universidade Federal de Goiás. Professor da Rede Estadual de Educação de Goiás, da Rede Municipal de Goiânia e Professor supervisor do Pibid. (leovanalves@yahoo.com.br) Goiânia-GO.

2 Licenciando em Geografia pela Universidade Federal de Goiás. Aluno bolsista do Pibid.

\author{
Recebido em: 08/09/2015 - Aprovado em: 14/11/2015 - Publicado em: 01/12/2015 \\ DOI: http://dx.doi.org/10.18677/Enciclopedia_Biosfera_2015_056
}

\begin{abstract}
RESUMO
O presente artigo procurou entender de que forma o conceito de território pode contribuir com as aulas de Geografia da educação básica. Para isso, partiu-se de uma pesquisa desenvolvida dentro do subprojeto de Geografia do PIBID (Programa Institucional de Bolsa de Iniciação à Docência). A fim de alcançar os objetivos propostos para este trabalho foram desenvolvidos alguns procedimentos de pesquisa: revisão bibliográfica (buscou-se o entendimento do significado teórico do território sob a perspectiva da teoria das relações de poder); observações na escola campo (para definição de estratégias metodológicas); e uma aula de intervenção pedagógica tendo como objetivo trabalhar as vertentes do conceito de território no ensino da Geografia escolar. Percebeu-se que o conceito de território é um conceito essencial para a compreensão do espaço e é fruto de controvérsias e discussões por parte de diversos autores ao longo do pensamento geográfico. Tal conceito torna-se potencializador do ensino de Geografia na medida em que discute e analisa práticas espaciais. Tais práticas espaciais estão inseridas em diferentes territórios, dos quais os alunos podem fazer parte ou não, e esses elementos são fundantes para instigar os alunos a conhecerem as imbricadas relações de poder e de identidade que estão inseridas nestes territórios. Também é potencializador trabalhar com esse conceito no ensino de Geografia para que os alunos possam atuar democraticamente na constituição de territórios da sociedade da qual fazem parte, compreendendo, assim, os conflitos territoriais de pequenas e grandes escalas que caracterizam a sociedade.
\end{abstract}

PALAVRAS-CHAVE: Geografia escolar. Pibid. Território.

\section{TERRITORY AND GEOGRAPHY SCHOOL : REFLECTIONS FROM TEACHING STUDENTS FELLOWS PIBID PERFORMANCE}

\footnotetext{
ABSTRACT

This article aims to understand how the concept of territory may contribute to Geography lessons of basic education. For this, it started with a research developed within the Geography of subproject PIBID (Institutional Program Initiation Purse in
} 
Teaching). In order to achieve the proposed objectives for this work were developed some research procedures: literature review (we sought to understand the theoretical significance of the territory from the perspective of the theory of power relations); observations in the field school (for definition of methodological strategies); and an educational intervention class aiming to work sheds the territory of concept in school geography teaching. It was felt that the concept of territory is a key concept for understanding the space and is the result of controversies and discussions by various authors over the geographical thought. This concept becomes enhancer teaching geography in that discusses and analyzes spatial practices. Such spatial practices are embedded in different territories, of which students can take part or not, and these elements are foundational to instigate students to know the intertwined relationships of power and identity that are embedded in these territories. It is also potentiating work with this concept in teaching geography for students to act democratically in the constitution of territories of society to which they belong, comprising thus territorial conflicts large and small scales that characterize the society.

KEYWORDS: School Geography. Pibid. Territory.

\section{INTRODUÇÃO}

O conceito de território como categoria de análise do espaço geográfico está aglutinado em torno de vários outros conceitos e fatos cotidianos que são focos de análise da Geografia, e que estão sempre presentes em discussões a cerca de questões relevantes de ordem política que são expressamente divulgados nos meios de comunicação nos dias de hoje. Em um sentido epistemológico, a palavra território vem do latim territorium, que significa pedaço de terra apropriado, em que o termo "terra" é bastante adequado, pois vai destacar sua relação com a terra, ou seja, como uma parcela do espaço onde se originam relações materiais e ideológicas (CRESPO, 2010).

De acordo com SOUZA (2003) o conceito de território perpassa por diversos elementos que exemplificam essa categoria de análise, no qual pode-se destacar a constituição enquanto elemento de poder, que se evidencia através da atuação do Estado, ou pelas múltiplas relações de poder e dominação exercida na gestão regional e local e difundida por poderes individuais e grupos que defendem seus interesses a partir das relações de soberania e supremacia dentro de um determinado espaço.

Buscando entender de que forma este conceito pode contribuir com as aulas de Geografia da educação básica este artigo é fruto de uma pesquisa desenvolvida dentro do subprojeto de Geografia do PIBID (Programa Institucional de Bolsa de Iniciação à Docência). O programa é financiado pela Coordenação de Aperfeiçoamento de Pessoal de Nível Superior (Capes) e oferece bolsa para estudantes de cursos de licenciatura plena, para que eles exerçam atividades pedagógicas em escolas públicas de ensino básico, aprimorando sua formação e contribuindo para a melhoria de qualidade dessas escolas. Para que os alunos sejam acompanhados e orientados, há bolsas também para coordenadores e supervisores.

Desta forma, a experiência didática dos alunos do PIBID nas aulas de Geografia de uma escola pública da rede municipal de ensino de Goiânia torna-se o ponto de partida para a análise e discussão do conceito de território como potencializador do ensino da Geografia escolar. É importante acentuar que desde a institucionalização da Geografia na Alemanha, com o intuito de formar professores 
de ensino básico, o conceito de território foi trabalhado para a formação de uma identidade nacional (estado-nação) do povo alemão (CASSOL, 2001). Neste sentido, o conceito responde a diversas pretensões para o ensino ajudando os alunos a entenderem a dinâmica espacial do poder nas diferentes escalas de relações sociais.

\section{MATERIAL E MÉTODOS}

A fim de alcançar os objetivos propostos para este trabalho de investigação desenvolvem-se alguns procedimentos de pesquisa. Em primeiro lugar, foi realizada uma revisão bibliográfica em livros, revistas e anais de eventos que trouxesse no título a temática território. Para isso, foi feito um levantamento no site da biblioteca central da Universidade Federal de Goiás com as palavras-chave "território e Geografia". Nesta pesquisa, foram levantados 114 registros dos quais 11 foram selecionados por trazerem o entendimento do significado teórico do território sob a perspectiva da teoria das relações de poder.

Em seguida, foram realizadas cinco observações de aulas do professor supervisor em turmas de $9^{\circ}$ ano do Ensino Fundamental de uma escola municipal da rede de ensino de Goiânia entre os meses de maio e junho de 2015. Durante as observações os alunos do Pibid realizavam anotações em um caderno de registro analisando aspectos como a relação do professor com os alunos, as motivações dos alunos e os conteúdos que estavam sendo trabalhados. Em seguida, foram definidas estratégias metodológicas para a realização das aulas como, por exemplo, o uso de mapas e a utilização do filme "Diamante de Sangue".

A partir destas observações e da definição das estratégias metodológicas foi proposta uma aula de intervenção pedagógica a ser trabalhada juntamente com o professor supervisor tendo por base as vertentes do conceito de território no ensino da Geografia escolar.

\section{RESULTADOS E DISCUSSÃO \\ Vertentes para o trabalho com o conceito de território}

O território tem uma dimensão tanto espacial quanto temporal, podendo ser feito e desfeito a todo o momento. A partir do levantamento bibliográfico, das observações e da experiência pedagógica vivenciada pelos estudantes do Pibid, foi possível perceber que dentre as diversas concepções de território, as mais difundidas e que marcam a tradição deste conceito são aquelas que enfatizam a ligação com relações de poder. Por assim dizer, território é um espaço definido e delimitado a partir de relações de poder (SOUZA, 2003).

Como por exemplo, uma rua que durante o dia serve para o deslocamento de pessoas e carros, atendendo ao comércio de determinado setor e durante a noite, em dias específicos da semana, torna-se palco de uma feira ao ar livre. Neste exemplo, os alunos podem além de notar o conceito do cotidiano, perceber as diferentes funcionalidades do espaço atribuídas pelo comércio no ciclo de turnos (durante o dia circulação e à noite feira ao ar livre), percebendo assim as diferentes territorialidades. Este exemplo auxilia também na compreensão da disputa e delimitação territorial que ocorre em várias escalas demonstrando como um mesmo espaço está incluso em diferentes escalas de territórios.

Tendo por base esta perspectiva, foi possível estabelecer um quadro traçando as vertentes para o trabalho com o conceito de território no ensino da Geografia escolar (quadro 1). 


\begin{tabular}{|l|l|}
\hline \multicolumn{2}{|l|}{ QUADRO 01- Vertentes básicas para o trabalho com o conceito de território. } \\
\hline Política ou jurídico-política & $\begin{array}{l}\text { O território é visto como espaço delimitado e } \\
\text { controlado, através do qual se exerce um } \\
\text { determinado poder. }\end{array}$ \\
\hline Cultural ou simbólico-cultural & $\begin{array}{l}\text { Aquele que prioriza a dimensão simbólica e mais } \\
\text { subjetiva, em que o território é visto, sobretudo, } \\
\text { como produto da apropriação/valorização de um } \\
\text { grupo em relação ao seu espaço vivido. }\end{array}$ \\
\hline Econômica & $\begin{array}{l}\text { Enfatiza-se a dimensão espacial das relações } \\
\text { econômicas; o território é visto como fonte de } \\
\text { recurso ou é incorporado no embate entre classes } \\
\text { sociais ou na relação capital/trabalho, como produto } \\
\text { da divisão territorial do trabalho. }\end{array}$ \\
\hline
\end{tabular}

Elaboração: autores

A partir da análise do Quadro 01 percebe-se que o conceito de território como uma categoria de análise do espaço geográfico, é de total pertinência para a compreensão do espaço produzido e vivido, sendo que este conceito vai tratar do espaço delimitado por fronteiras, sejam elas definidas pelo homem ou pela natureza. No entanto, essas fronteiras muitas vezes não são visíveis, no qual através de fundamentações advindas do conceito de território permitem a compreensão crítica e sensata do espaço e que muitas vezes são negligenciadas pelo senso comum.

Desta forma, este conceito é bastante amplo dentro da Geografia, sendo utilizado como um recorte temático muito útil e eficaz no estudo de variados fenômenos geográficos, porém, de acordo com CRESPO (2010) essa categoria de análise se destaca por enfocar assuntos provenientes de outras disciplinas, em que pode-se citar a Geopolítica, a Antropologia, as Ciências Sociais, a Biologia, entre outros. MARIGNIER (2013), por sua vez, também destaca que o debate sobre o conceito de território se consolidou como um dos grandes pilares do pensamento geográfico, e se modificou radicalmente a partir das mudanças ocorridas na Geografia levando-se em conta as diferentes fases e metodologias que foram empregadas em cada período nos estudos e pesquisas relacionadas aos fenômenos geográficos decorrentes em cada época, em que o conceito sofreu profundas transformações principalmente com a transição da Geografia Quantitativa para a Geografia Crítica.

Com base nessas modificações nas pesquisas relacionadas a este conceito, é importante ressaltar autores que difundiram o conceito de território dentro do âmbito geográfico, tais como RATZEL (1990) que faz interligação entre o território e o povo que o habita, este autor concebe o território como elemento da sociedade e do Estado, conceituando-se então que há uma intrínseca relação entre HomemTerra e Sociedade-Território, em que a sociedade era inteiramente dependente a partir do território que lhe refere.

A partir dessa concepção, RATZEL (1990) elabora o conceito de Espaço Vital que é de íntegra relevância para o estudo do território, em que este conceito se baseia nas condições espaciais e naturais para a manutenção ou consolidação do poder do Estado sobre o território. Seriam as condições naturais disponíveis que contribuiria para o fortalecimento de uma dada sociedade ou povo, desta forma, aquelas populações que dispusessem de melhor espaço vital estariam mais aptas a se desenvolver e a conquistar outros territórios, originando-se então o "determinismo 
geográfico" que prediz que o homem é produto do meio, ou seja, este estaria submetido às condições naturais que determinam a vida em sociedade.

Além de RATZEL (1990), outros autores abordam o conceito de território de formas diferentes. RAFFESTIN (1993) afirma que o território se apoia no espaço, mas não é o espaço, é uma produção a partir do espaço. Dessa forma, é uma produção por causa de todas as relações que envolvem, inscrevendo-se em um campo de poder.

SANTOS (1996) aponta que o território são formas, objetos e ações, sinônimo de espaço humano, espaço habitado. Assim, quando quisermos definir qualquer pedaço do território, deveremos levar em conta a interdependência e a inseparabilidade da materialidade, que inclui a natureza e o seu uso, e a ação humana, isto é, o trabalho e a política.

Além de evidenciar toda a natureza e sua apropriação que originam relações de trabalho e política, SANTOS (1996) traz outros elementos para a discussão, apresentando o território como uma junção integral que formam a natureza em seu aspecto superficial e visível, ou seja, o território seria uma totalidade que estaria em constante transformação decorrentes da grande movimentação da sociedade, o que propicia a historicidade do espaço.

O território possui também um sentido relacional, em que as espacialidades possuem importante papel na construção das relações espaciais. SOUZA (2003) aponta que o território é um espaço definido e delimitado por e a partir de relações de poder. A questão primordial não é, na realidade, quais são as características geoecológicas e os recursos naturais de uma área, e sim quem domina ou influencia quem nesse espaço e de que forma. O conceito de território, do ponto de vista da ciência geográfica, tende a enfatizar a materialidade do território em suas múltiplas dimensões, inclusive a relação sociedade-natureza. HAESBAERT (2004) afirma que território possui dois significados: poder e dominação/apropriação. Assim, para o autor, dentro de um mesmo espaço podem coexistir territorialidades diferentes, sobrepostas ou paralelas. Os sujeitos em seus territórios são condicionados pelo poder, exercendo ação sobre este território.

Nesta perspectiva, o território não pode ser percebido apenas como uma posse ou uma entidade exterior à sociedade que o habita, ou seja, é uma parcela de identidade, fonte de uma relação de essência afetiva ou mesmo amorosa ao espaço. Percebe-se, assim, que o conceito de território apresentou diferentes nuances ao longo do pensamento geográfico, mas, atualmente, tem o sentido ligado sobretudo às relações de poder que se estabelecem em campos de força e às relações de identidade.

\section{O conceito de território na Geografia escolar}

Com base nas referências teóricas e didáticas a cerca do conceito de território é indispensável filtrar e selecionar algumas fundamentações que vão auxiliar o processo de ensino-aprendizagem dos alunos, uma vez que, diferentes metodologias, métodos e técnicas que envolvem este conceito podem ser utilizados para exemplificar de uma melhor forma os conteúdos que constituem o espaço geográfico.

SANTOS (2015) destaca que o conceito de território potencializa o ensino de Geografia, uma vez que as práticas espaciais estão inseridas em diferentes territórios, dos quais os alunos podem fazer parte ou não, e esses elementos são importantes para instigar os alunos a conhecerem as imbricadas relações de poder e de identidade que estão inseridas nestes territórios. 
Desta forma, é interessante realizar em sala de aula uma interconexão entre o cotidiano de vivência do aluno com os conteúdos trabalhados e presentes no currículo escolar, o que torna mais atrativo e dinâmico o processo de ensinoaprendizagem, não deixando de lado todo o contexto didático que o conceito de território está incluído, o que acaba potencializando e otimizando o ensino deste conceito no ensino da educação básica, contribuindo para que os alunos possam atuar democraticamente na constituição de territórios da sociedade da qual fazem parte, compreendendo, assim, os conflitos territoriais de pequenas e grandes escalas que caracterizam a sociedade.

A partir do levantamento bibliográfico em torno do conceito de território foram destacados alguns autores que trazem importantes contribuições em torno do conceito, sendo: CAVALCANTI (2006), SAQUET (2012) e SOUZA (2012). Através deste levantamento foi possível perceber que o conceito de território muitas vezes é tratado de forma simplista no cotidiano das aulas de Geografia da educação básica, sendo, desta forma, concebido como forma de uma divisão administrativa, que envolve fronteiras e um espaço delimitado por representações cartográficas.

CAVALCANTI (2006) destaca que o trabalho com a Geografia na educação básica baseia-se no desenvolvimento de uma educação geográfica que possa ajudar os alunos a analisarem os conhecimentos da relação direta e cotidiana com o espaço vivido, contribuindo para o desenvolvimento de modos do pensamento geográfico, internalizando assim, métodos e procedimentos de captar a realidade.

A formação de conceitos geográficos abrangentes é segundo CAVALCANTI (2006) uma das ferramentas fundamentais para a compreensão de diversos espaços, para localizar e analisar os significados dos distintos lugares e sua relação com a vida cotidiana. $O$ desenvolvimento de um modo de pensar geográfico mais amplo e abstrato requer, portanto, a formação de conceitos pelos alunos: implica a busca de significados e sentidos dados pelos professores aos diversos temas trabalhados em sala de aula.

E dentro desta perspectiva encontra-se o conceito de território. CAVALCANTI (2006) afirma que este conceito envolve imbrincadas relações de poder, sejam poderes do Estado, de grupos e individuais/ nós e redes/ limites/ fronteiras. Desta forma, ao trabalhar com o conceito de território nas aulas de Geografia alguns aspectos devem ser enfatizados e o primeiro deles é a relação de poder. Este autor destaca também que o conceito de território tem uma larga utilização na história da Ciência Geográfica e no ensino, está presente em diversos conteúdos que compõem o programa curricular do ensino fundamental e médio. Desta forma, faz-se necessário trazer esses conceitos para a sala de aula, através da interação com o aluno, por exemplo. Como proposta de sistematização do conceito de território para o ensino da Geografia escolar, CAVALCANTI (2006) apresenta esses elementos como os mais específicos: o poder (poderes do Estado, de grupos e individuais, os nós, as redes, as fronteiras e limites), a identidade (as sociedades multiculturais) e 0 campo de forças (flexíveis, inflexíveis, estáveis, instáveis).

SOUZA (2003) analisa que o território pode ser definido a partir de relações de poder e soberania. Nesta perspectiva, são vários os aspectos do cotidiano que podem ser retratados em sala de aula, tais como: a questão do tráfico de drogas nas favelas do Rio de Janeiro, a disputa por território por parte de grupos extremistas e tribais no continente africano, entre outros, que são acontecimentos que estão presentes na mídia e que podem ser utilizados como ponto de partida para a discussão de conteúdos escolares. 
Diante dessas limitações, SOUSA (2012) destaca que é primordial citar algumas abordagens que são negligenciadas em livros didáticos e que é de total relevância em conteúdos que se referem ao território brasileiro, entre eles:

- O território é tratado de forma simplista: o emprego de conceitos são subexplorados como recursos de análise e síntese em sala de aula na interpretação dos fenômenos ou situações de ordem espacial, porém, é comum vê-los de forma simplificada e superficial;

- O território brasileiro muitas vezes é citado somente pelo extenso território terrestre. E desta forma, aspectos como território terrestre, aéreo, marítimo e o subsolo, devem ser elucidados com 0 intuito de exemplificar questões de fiscalização e relações de poder atreladas a questões econômicas, o que vai elencar dimensões como fatores econômicos que cada um proporciona, tais como, as relações de poder e a questão zonal do território, invocando o controle político, cultural e econômico do governo brasileiro.

SAQUET (2012) destaca que o conceito de território em âmbito escolar se limita muito a definição de "Estado-Nação", restrito à formação do Brasil, como área com características específicas (população, relevo, rios, clima, vegetação etc.), o que parcialmente sedimenta os debates de pesquisas e publicações sobre essa categoria de análise geográfica.

Estas reflexões apontam que o conceito de território aplicado no ensino escolar de Geografia pode ser trabalhado de várias formas em sala de aula, SAQUET (2012) também apresenta algumas questões que devem ser observados ao trabalhar este conceito em sala de aula:

- A necessidade de se trabalhar o conhecimento dos educandos acerca do conceito de território a partir da leitura de imagens em livros didáticos;

- O trabalho com seleção e elaboração de esquemas de investigação, que desenvolvam a observação dos processos de formação e transformação dos territórios;

- A introdução do estudo partindo da escala local, com observações do espaço que os alunos vivem;

- O uso da expressão gráfica, de formas geométricas para elucidar o conceito de território com a realidade do aluno e permitir um melhor entendimento do local em que vive (uso contínuo de mapas que expressem as territorialidades locais).

Desta forma, é notável perceber que devido a grande abrangência teórica do conceito de território, existem várias técnicas e métodos para se trabalhar este conceito em um contexto didático que contribua significativamente com o ensino de Geografia, e que ao mesmo tempo assegure aos alunos uma noção espacial mais crítica do lugar onde vivem. SOUSA (2012) destaca que é fundamental estar atento a algumas questões ao trabalhar este conceito na educação básica, tendo a atenção na aplicação do conceito no processo didático. Evitar tornar essa definição rasa e superficial que não tenha qualquer tipo de precisão no conteúdo lecionado, delimitar e ter critério para inserir o conceito em qualquer que seja a esfera da sociedade (econômica, cultural e política) e por fim, evitar um aprofundamento desnecessário do conceito, fazendo com que a linguagem acadêmica se encaixe no contexto escolar de forma competente.

A construção do conceito território segundo SOUSA (2012) pode ser erguida a partir do exemplo empírico envolvendo escalas de território que se associem aos "micropoderes" num espaço imediato, isto é, a casa, a rua, o bairro (na escala local), espaços regionais e nacionais até chegar à escala global. 
Faz-se necessário também demonstrar que o território é resultado da ação dos atores (governos, empresas, organizações não governamentais, associações civis entre outros) conforme os interesses e, mais do que isto, exemplificar casos de ações expositivas derivadas de ações práticas ou movimentos sociais legítimos que incentivem o exercício da cidadania e ofereçam ao aluno visão de que é possível ser um sujeito ativo nas mudanças de sua comunidade onde ele se encontra inserido. $O$ conceito de território revela-se assim, de acordo com SOUSA (2012), como interessante para estabelecer abordagens sugestivas de interdisciplinaridade.

Em uma mesma perspectiva, FERRETO (2012) apresenta a necessidade de desenvolver o conhecimento dos educandos acerca do conceito de território tendo por base a leitura de imagens em livros didáticos. Desta forma, torna-se possível a seleção e elaboração de esquemas de investigação que possam desenvolver a observação dos processos de formação e transformação dos territórios, sempre tendo em vista as relações de trabalho, a incorporação de técnicas e tecnologias e o estabelecimento de redes sociais.

Nestes esquemas de investigação esta mesma autora destaca que deve-se priorizar o reconhecimento da aparência das formas visíveis e concretas do espaço geográfico atual e a sua essência, ou seja, os processos históricos, construídos em diferentes tempos, e os processos contemporâneos, o conjunto de práticas dos diferentes agentes, que resultam em profundas mudanças na organização e no conteúdo do território vivido.

\section{A experiência a partir das observações e da intervenção de alunos bolsistas do pibid}

No primeiro semestre do ano letivo de 2015 a partir das atividades desenvolvidas dentro do subprojeto de Geografia do PIBID, um grupo de cinco estudantes de licenciatura em Geografia foram para uma escola da rede municipal de educação de Goiânia para iniciarem suas atividades de acordo com o cronograma deste subprojeto. Durante todo o semestre foram realizadas atividades de observação e intervenção nas aulas de Geografia sob a supervisão do professor supervisor designado pelo programa.

A escola-campo desta investigação localiza-se na região Noroeste de Goiânia, uma região periférica da cidade e assim como as demais escolas do município, esta organizada em Ciclos de Formação e Desenvolvimento Humano (GOIÂNIA, 2012). Os Ciclos de Formação e Desenvolvimento Humano, em Goiânia, preveem a organização dos educandos da seguinte forma: Ciclo I - Ciclo da Infância (6 a 8 anos), Ciclo II - Ciclo da Pré-adolescência (9 a 11 anos) e o Ciclo III - Ciclo da Adolescência (12 a 14 anos). Nessa organização, a matrícula é feita tendo-se como referência as idades dos educandos que comporão os agrupamentos "de origem". Após essa organização, avaliações constantes e sistemáticas são realizadas.

Uma avaliação inicial de todos os educandos ingressos naquele ciclo e agrupamento, com caráter diagnóstica é aplicada e o resultado dessa avaliação inicial é correlacionado observando-se a idade, escolaridade, tempo de ciclo, frequência e a trajetória escolar. A partir disso, o coletivo de professores têm as condições necessárias para planejar as ações pedagógicas, inclusive as possibilidades de movimentação dos educandos nos agrupamentos de cada ciclo (GOIÂNIA, 2012).

Nessa proposta, a prática docente é entendida como ponto de partida para o desenvolvimento do processo de formação continuada e são as práticas que 
consideram o conhecimento teórico e científico como mediação para compreensão e a atuação docente no contexto educacional. O processo de formação continuada nessa perspectiva deve ponderar também o domínio dos conteúdos a serem trabalhados e de suas possibilidades metodológicas, a relação entre teoria e prática, a leitura e a escrita como prática social e constitutiva do trabalho docente, o comprometimento ético do profissional da educação com a inclusão social, a aprendizagem do aluno e a permanência na escola com qualidade e o desenvolvimento de uma perspectiva investigativa e reflexiva sobre a prática docente.

A escola se divide em dois espaços físicos: a sede e o anexo, onde algumas turmas do ciclo III (incluindo as turmas que foram observadas, do $7^{\circ} \mathrm{e} 9^{\circ}$ ano) têm aula. $O$ anexo é um prédio comercial alugado pela Secretaria Municipal de Educação (SME) e está próximo à sede da mesma. O prédio comercial, onde está o anexo, teve as salas adaptadas para se tornarem salas de aula, que apesar de alguns problemas fornece um bom auxílio para a escola.

A partir das observações realizadas em sala de aula, foi possível que os alunos do Pibid pudessem conhecer o perfil dos alunos, tais como, os aspectos cognitivos, socioeconômicos e culturais. Apesar de todos os problemas (casos de alunos analfabetos em turmas de $7^{\circ}$ e $9^{\circ}$ ano, por ex emplo), no geral as turmas apresentam um bom rendimento e há sim muitos alunos com bom desempenho escolar.

O desafio enfrentado pelos professores de escolas periféricas como a escola que foi campo desta experiência didática é o de aprender a lidar com a realidade vivenciada por muitos dos alunos que ali estudam e também utilizar estas vivências como apoio para os conteúdos ministrados em sala de aula. O objetivo de trabalhar conceitos, como o de território, em sala de aula é munir os alunos de conhecimentos que possam mudar a forma com que encaram a própria realidade. Neste sentido, pretende-se ao trabalhar o conceito de território, fazer com que os alunos ultrapassem a barreira do senso comum de que tal conceito está preso às delimitações do Estado-Nação.

A partir da atuação dos alunos bolsistas em sala de aula, primeiramente apenas como observadores, foi possível notar quais eram as maiores dificuldades dos alunos, para em seguida, poder elaborar aulas de intervenção juntamente com o professor supervisor que atua na escola. O objetivo central destas aulas era atingir a maior quantidade de alunos, no sentido de tornar o processo de ensino e aprendizagem algo mais interessante a estes alunos tendo como referência os saberes prévios.

Dentro dessas observações foi possível notar que uma das maiores dificuldades em sala de aula é conseguir a atenção dos alunos, uma vez que, muitos não estavam atentos a explicação do professor. Durante as primeiras aulas de observação, foi possível analisar a postura dos alunos, primeiramente com a presença dos alunos bolsistas a sala ficou mais quieta, porém no decorrer das semanas, percebeu-se que os alunos por adquirirem uma maior proximidade com os bolsistas ficaram mais a vontade. Este fato trouxe aspectos de duas dimensões: os alunos tornaram-se mais participativos com importantes participações durante as aulas, fazendo as atividades e tirando dúvidas. E por outro lado, estes também começaram a conversar mais entre si durante a explicação do professor.

Com base nos levantamentos bibliográficos e as observações realizadas, foi possível ter maior preparação para a inserção docente na escola campo. A proposta de intervenção se dividiu em algumas etapas: no primeiro momento trabalhou-se 
com mapas, por acreditar que, desta forma, os alunos poderiam visualizar de uma melhor forma o conteúdo proposto. O uso de mapas para visualização representativa do espaço é uma excelente ferramenta para tornar o processo de aprendizagem mais significativo. Em trabalhos com mapas acabados (no caso de consulta ao atlas geográfico, por exemplo), a exposição da área em foco seguiu de uma interpretação apurada em que os elementos cartográficos foram explicitados em detalhes.

A decodificação da legenda, a observação dos limites da área, a distribuição e distância dos objetos representados e suas relações com as redes distribuídas pelo espaço são aspectos fundamentais para o pensamento reflexivo da questão territorial posta em estudo. O uso do mapa também pode ser feito a partir de atividade que envolva a produção do próprio aluno, ou seja, incentivá-lo a produzir mapas e orientá-lo a definir critérios de classificações e correlações das formas gráficas do mapa são exemplos de atividades proveitosas no entendimento do tema em que um dado território ou territorialidade é foco do estudo.

Para trabalhar com conteúdos de disputas territoriais, muito comum nas séries do ensino básico, foi realizado um levantamento de alguns filmes que poderiam ser utilizados, neste caso o filme selecionado foi "Diamante de sangue". $O$ objetivo com a utilização deste recurso foi o de articular uma discussão entre território e o conteúdo do continente africano. Assim, após realizar a exibição do filme, na aula seguinte foi realizado um debate para que os alunos pudessem expor suas visões e entendimentos do que estava sendo objeto de estudo. Foi possível, desta forma, alcançar bons resultados, contribuindo com o objetivo de construir com o aluno o conteúdo proposto, porém de uma maneira diferente, buscando outras formas de despertar a atenção dos alunos.

Quando os estudos foram aprofundados no conceito de território, percebeu-se as diversas possibilidades para o seu trabalho em sala de aula. Na prática, o território se espacializa de diferentes formas e em diferentes escalas, tornando-o um conceito bem didático para ser trabalhado, propiciando exemplificações presentes no cotidiano dos alunos na escola ou fora dela (nas proximidades da escola, onde também residem os alunos e suas famílias).

\section{CONCLUSÃO}

A partir desta investigação percebe-se que o conceito de território é um conceito essencial para a compreensão do espaço e, assim como todos os conceitos geográficos, também é fruto de controvérsias e discussões por parte de diversos autores ao longo do pensamento geográfico, sendo submetido a tentativas de redefinição e depuração. Percebe-se também que o conceito de território apresentou diferentes nuances ao longo do pensamento geográfico, mas, atualmente, tem seu sentido ligado sobretudo às relações de poder que se estabelecem em campos de força e às relações de identidade.

O conceito de território torna-se um importante potencializador do ensino de Geografia na medida em que discute e analisa práticas espaciais. Ressalta-se que estas práticas espaciais estão inseridas em diferentes territórios, dos quais os alunos podem fazer parte ou não, e esses elementos são fundantes para instigar os alunos a conhecerem as imbricadas relações de poder e de identidade que estão inseridas nestes territórios. Também é potencializador trabalhar com esse conceito no ensino de Geografia para que os alunos possam atuar democraticamente na constituição de territórios da sociedade da qual fazem parte, compreendendo, assim, 
os conflitos territoriais de pequenas e grandes escalas que caracterizam a sociedade.

\section{REFERÊNCIAS}

CAVALCANTI, L. S. Bases teórico-metodológicas da Geografia: uma referência para a formação e a prática de ensino. In: CAVALCANTI, I. S (org.) Formação de professores: concepções e práticas em Geografia. Goiânia: Vieira, p. 2750.2006 .

CRESPO, M. P. Um estudo sobre o conceito de território na análise geográfica. III Encontro de Geografia - A Geografia e suas vertentes: reflexões. Rio de Janeiro, 2010. Anais... Rio de Janeiro, 2010.

CASSOL, R. et al. Considerações sobre a temática ambiental em Geografia. In: Geografia: Ensino e Pesquisa. V. 11, N. 01. Santa Maria, p. 1-8.2001.

MARIGNIER, M. V. O. Território, geografia e ciências sociais: Notas Históricoepistemológicas. In: Revista Continentes. Ano 02, N. 02, Rio de Janeiro, 2013.

FERRETO, L. Trabalhando o conceito de território no ensino fundamental. 10 Encontro Nacional de Práticas de Ensino de Geografia - ENPEG. 2009, Porto Alegre. Anais... Porto Alegre, 2009.

GOIÂNIA. Secretaria Municipal de Educação. Proposta Político-Pedagógica para Educação Fundamental da Infância e da Adolescência. Goiânia, 2012.

HAESBAERT, R. O mito da desterritorialização: do "fim dos territórios" à multiterritorialidade. Rio de Janeiro: Bertrand Brasil, 2004.

RAFFESTIN, C. Por uma geografia do poder. São Paulo: Ática, 1993.

RATZEL, F. Geografia do homem (Antropogeografia). In: MORAES, Antônio C. R. (Org.). Ratzel. São Paulo: Ática, p. 32-107. 1990.

SANTOS, M. O retorno do território. In: SANTOS, Milton; SOUZA, Adélia A. de; SILVEIRA, Maria Laura (Org.). Território: globalização e fragmentação. São Paulo: Hucitec, p.15-20. 1996.

SANTOS, L. A. Ensinar Geografia pela pesquisa: possibilidades de construção do pensamento espacial pelos alunos. 2015, 95f. Dissertação (Mestrado em Geografia), Instituto de Estudos Socioambientais, Universidade Federal de Goiás, Goiânia, 2015.

SAQUET, M. A. O território no ensino-aprendizagem de geografia. In: Geo UERJ. Ano 14, ํ․ 23, v. 2, 2ํㅗ semestre de 2012. p.699-716, 2012.

SOUSA, R. R. O conceito território no ensino da geografia: breves notas sobre abordagens negligenciadas. In: Geografia em Questão, v.05,n.2, Cascavel, p.149165.2012. 
SOUZA, M. J. L. de. O território: sobre espaço e poder, autonomia e desenvolvimento. In: CASTRO, I. E. de; GOMES, P. C. da C.; CORRÊA, R. L. (Orgs.). Geografia: conceitos e temas. Rio de Janeiro: Bertrand Brasil, p. 77116.2003. 